\title{
Case analysis of complete uterine rupture in a tertiary health care center
}

\author{
Mahija Sahu, Natasha H. K., Priyanka Mandpe*
}

Department of Obstetrics and Gynecology, Shriram Chandra Bhanj Medical College and Hospital, Cuttack, Odisha, India

Received: 08 October 2016

Accepted: 03 November 2016

\author{
*Correspondence: \\ Dr. Priyanka Mandpe, \\ E-mail: priyankamandpe@gmail.com
}

Copyright: () the author(s), publisher and licensee Medip Academy. This is an open-access article distributed under the terms of the Creative Commons Attribution Non-Commercial License, which permits unrestricted non-commercial use, distribution, and reproduction in any medium, provided the original work is properly cited.

\begin{abstract}
Background: To determine the incidence, etiology, risk factors, complications, treatment strategies, maternal and fetal outcome associated with complete rupture uterus.

Methods: This observational study was carried out in the Department of Obstetrics and Gynecology of Shriram Chandra Bhanj Medical College and Hospital, Cuttack, Odisha. The details of retrospective analysis of 52 cases of complete uterine rupture managed between July 2014 to April 2016 were reviewed.

Results: The incidence of uterine rupture was 1 in 353 deliveries $(0.28 \%)$. Most of the patients $(61.5 \%)$ presented belonged to age group of 26-30 years. The most common cause of rupture uterus was rupture of previous caesarean scar in 30 cases $(57.64 \%)$, whereas cepahalopelvic disproportion was predisposing factor in 18 cases (34.61\%) and malpresentation in 4 cases. In majority $80.76 \%$ of lower uterine segment was involved. Bladder injury was seen in 4 cases $(7.69 \%$ ) A most common form of management was rent repair in $53.84 \%$ cases. There were 2 maternal deaths with perinatal mortality rate being $100 \%$ associated with complete uterine rupture.

Conclusions: Rupture of uterus is a dire emergency with high incidence of maternal and fetal mortality and morbidity. Most cases of rupture uterus are preventable with good antenatal and intrapartum care, and proper identification of high risk factors. Early diagnosis and active surgical management will go a long way in reducing the maternal and fetal mortality and morbidity.
\end{abstract}

Keywords: Caesarean section, Hysterectomy, Mortality, Morbidity, Uterine rupture

\section{INTRODUCTION}

Maternal health has long been acknowledged to be the cornerstone in public health. Rupture of uterus is an obstetric emergency, where life of mother as well as fetus is in danger. Maternal mortality rate in India according to census 2011 is 167 per 1 lakh live births. It is a hazardous complication which accounts for $5-10 \%$ of all the maternal deaths in India. ${ }^{1}$ The perinatal mortality rate ranges from $80-90 \%$ The hospital based incidence of uterine rupture varies from 1 in 250-500 deliveries in developing countries to 1 in $3000-5000$ deliveries in developed countries.
In developing countries, the incidence is high due to majority of women originating from rural areas with poor antenatal care. Complete uterine rupture occurs when a full- thickness disruption of the uterine wall involving the overlying visceral peritoneum is present. By definition, it is associated with clinically significant uterine bleeding, fetal distress, protrusion or expulsion of the fetus and /or placenta into the abdominal cavity, need for prompt caesarean delivery and uterine repair or hysterectomy. In contrast to frank uterine rupture, uterine scar dehiscence involves the disruption and separation of a pre-existing scar. As there is increase in the incidence of previous caesarean section deliveries, hence it was found to be 
common cause of uterine rupture with previous caesarean scar.

Myercough has considered rupture of uterus in three different circumstances viz:

1. Rupture of uterus during pregnancy.

2. Rupture of the uterus during labor without dystocia.

3. Rupture of the uterus following obstructed labour or difficulty delivery. ${ }^{2}$

Rupture of unscarred uterus during labour may be either spontaneous, traumatic or rarely due to unknown causes. Traumatic factors include abdominal trauma, labor induction (by oxytocin or prostagladins), internal podalic version, assisted breech delivery and instrumental delivery. Spontaneous rupture is associated with cephalopelvic disproportion, malposition, malpresentation, delivery of macrosomic baby or grossly anomalous baby. Rupture may also develop spontaneously in grand multipara, congenitally abnormal uterus, in abnormal placental implantation, and in women with a history of an invasive mole.

The most critical aspects of treatment of uterine rupture are establishing a timely diagnosis and minimizing the time from onset of signs and symptoms until the start of definitive surgical treatment.

Identifying the high risk pregnancies for rupture uterus and their timely referral is an important step in secondary prevention. Different modes of management namely repair of rent, sub-total or total hysterectomy was practiced. The preference of management outcome varies in different centers.

\section{METHODS}

This is an observational study which was carried out in the department of obstetrics and gynecology of SCB Medical College and Hospital, Cuttack. All cases of rupture uterus admitted to the hospital from July 2014 to April 2016 were interviewed / history taken from patient's attendant, examined, treated and followed up.

Patient demographic variables like age, place of residence (rural/urban), socioeconomic status, parity, antenatal care in present pregnancy, gestational age, referral status, clinical presentation, previous obstetric and surgical history was recorded. A thorough clinical and obstetric examination was carried out. Obstetric risk factors like previous caesarean section, cephalopelvic disproportion, labor induction and instrumental delivery were recorded. The site of rupture, type of surgery performed, duration of hospital stay, blood transfusion, maternal and fetal outcome were documented. Mothers were followed throughout the postoperative period for evidence of sepsis, abdominal distension, wound infection, anemia, and also remote complications like vesico-vaginal fistula up to six weeks after discharge.
Different operations done in this study were uterine repair, subtotal hysterectomy and total hysterectomy.

\section{RESULTS}

A total of 18,395 deliveries were conducted from July 2014 to April 2016, and 52 cases of complete uterine rupture were managed. The incidence of uterine rupture was 1: 353 deliveries $(0.28 \%)$.

Majority of women (61.53\%) 32 cases belonged to 26-30 years (Table 1). $59.61 \%$ or 32 women were of second gravida, whereas primigravidas comprised of 6 cases (11.53\%). $63.08 \%$ of women belonged to low socioeconomic status. Majority of women 46 cases $(88.46 \%)$ came from rural area. 25 cases $(48.07 \%)$ had at least 1 to 3 antenatal visits, but 16 women $(30.76 \%)$ did not receive any antenatal care. Out of 52 cases, 1 booked case had rupture uterus when she was admitted in the antenatal ward, rest 51 cases were either referred or came directly to labour room.

Maximum number of ruptures $(80.7 \%)$ occurred at more than 37 weeks of gestation, but 4 cases $(7.6 \%)$ were seen in women with less than 28 weeks of gestation.

Table 1: Incidence of rupture uterus in relation to demographic variables.

\begin{tabular}{|c|c|c|}
\hline Characteristics & Number & Percentage \\
\hline \multicolumn{3}{|c|}{ Maternal age (years) } \\
\hline $21-25$ & 15 & 28.85 \\
\hline $26-30$ & 32 & 61.53 \\
\hline $31-35$ & 3 & 5.76 \\
\hline \multicolumn{3}{|l|}{ Parity } \\
\hline 0 & 6 & 11.53 \\
\hline 1 & 31 & 59.61 \\
\hline 2 & 9 & 17.30 \\
\hline$>3$ & 6 & 11.53 \\
\hline \multicolumn{3}{|c|}{ Birth weight (kilograms) } \\
\hline$<2.5 \mathrm{~kg}$ & 7 & 13.46 \\
\hline $2.5-3.5 \mathrm{~kg}$ & 35 & 67.30 \\
\hline$>3.5 \mathrm{~kg}$ & 10 & 19.23 \\
\hline \multicolumn{3}{|l|}{ Antenatal visits } \\
\hline 0 & 16 & 30.76 \\
\hline $1-3$ & 25 & 48.07 \\
\hline$>3$ & 11 & 21.15 \\
\hline
\end{tabular}

Table 2 Women with previous history of caesarean section were 30 cases $(57.69 \%)$, and 8 women had a previous history of suction and evacuation. Most primipara belonged to post caesarean group. Malpresentation was the etiological factor in 4 cases (7.69\%) and cephalopelvic disproportion in 18 cases $(34.61 \%)$.

Traumatic rupture accounted for $13.46 \%$ of the cases $(7$ cases). Most of the traumatic rupture was due to 
injudicious use of oxytocin or prostaglandins for induction or augmentation of labour. Women with third and fourth gravida were found to be more prone to rupture uterus, due to presence of other risk factors like cephalopelvic disproportion and injudicious use of oxytocis.

Table 2: Risk factors.

\begin{tabular}{|lll|}
\hline Risk factors & Number & Percentage \\
\hline Spontaneous rupture & \multicolumn{3}{l|}{} \\
Cephalopelvic disproportion & $18^{*}$ & 34.61 \\
Multiparity & 15 & 28.84 \\
Malpresentation & 4 & 7.69 \\
\hline Iatrogenic / Traumatic rupture & $7 *$ & 13.46 \\
\hline Scar rupture & 30 & 57.69 \\
Previous one caesarean & 29 & 55.76 \\
Previous two caesarean & 1 & 1.92 \\
\hline History of MTP** & 6 & 15.38 \\
\hline *In some cases there was more than one risk factor \\
**MTP-Medical termination of pregnancy
\end{tabular}

The most common presenting features of rupture uterus were pain abdomen, palpation of fetal parts superficially and absent fetal heart sounds. Out of 52 cases of uterine rupture, 48 cases $(92.3 \%)$ occurred during labor and reaming 4 cases $(7.7 \%)$ during antepartum period.

The most site of rupture was found to the anterior surface of uterus in 41 cases $(78.84 \%)$, followed up posterior surface $(13.46 \%)$. Lower segment was involved in majority of cases (80.76\%), whereas both upper and lower segment was involved in 4 cases (Table 3 ).

Table 3: Site of rupture.

\begin{tabular}{|lll|}
\hline Site of rupture & Number & Precentage \\
\hline Anterior surface & 41 & 78.84 \\
\hline Posterior surface & 7 & 13.46 \\
\hline Lateral surface & 4 & 7.69 \\
\hline Upper segment & 6 & 11.53 \\
\hline Lower segment & 42 & 80.76 \\
\hline Both (upper + lower) segment & 4 & 7.69 \\
\hline
\end{tabular}

The associated internal injuries with the rupture of uterus. 33 cases $(63.46 \%)$ had no associated injury, colporrhexis was seen $15.38 \%$ (8 cases), 7 cases $(13.46 \%)$ had broad ligament hematoma and 4 cases (7.69\%) had bladder injury. It was possible to repair the uterine rent in $53.84 \%$ (28 cases), while in $46 \%$ cases subtotal/total hysterectomy was done (Table 4 ).

Table 4: Management.

\begin{tabular}{|lll|}
\hline & Number & Percentage \\
\hline Rent repair & 28 & 53.84 \\
\hline Subtotal hysterectomy & 10 & 19.23 \\
\hline Total hysterectomy & 14 & 26.92 \\
\hline
\end{tabular}

Maternal death occurred in 2 cases (3.8\%), both postoperative. One due to hemorrhagic shock and second due to septicemia. Perinatal mortality rate was very high in our study $100 \%$. There was no live birth associated with complete uterine rupture.

Table 5: Mentions the various postoperative complications of complete rupture uterus.

\begin{tabular}{|lll|}
\hline & Number & Percentage \\
\hline Pyrexia & 12 & 23.07 \\
\hline Wound infection & 5 & 9.61 \\
\hline Paralytic ileus & 2 & 3.84 \\
\hline Urinary tract infection & 10 & 19.23 \\
\hline Septicemia & 3 & 5.76 \\
\hline Vesico-vaginal fistula & 2 & 3.84 \\
\hline Shock & 2 & 3.84 \\
\hline Fetal death & 52 & 100 \\
\hline Maternal death & 2 & 3.84 \\
\hline
\end{tabular}

34 cases of rupture $(65.38 \%)$ required hospital stay up to 7-14 days; whereas $19.2 \%$ (10 cases) had prolonged hospital stay of more than 21 days.

\section{DISCUSSION}

Uterine rupture is a serious obstetric complication, with a high maternal and fetal morbidity and mortality, particularly in less and least developed countries. In a WHO systematic review of maternal mortality and morbidity, the prevalence of the uterine rupture in case of previous caesarean section was found to be $1 \% .^{3}$ In our study, incidence of complete uterine rupture was 1: 353 deliveries $(0.28 \%)$ which was comparable to other Indian studies. Among the developing countries, the incidence varied in $1: 124(0.8 \%)$ in Ghana, $0.74 \%$ in Pakistan, $0.9 \%$ in Nepal and $2.8 \%$ in Ethiopia. ${ }^{4-7}$ The incidence in developed countries is recorded at least ten times lower $(0.035 \%)$. This wide variation in incidence is due to socio-economic factors, cultural practices and lack of access between to antenatal and intrapartum care.

Most of the patients $(61.53 \%)$ in our study belonged to age group of 26-30 years. In of the Indian study reported by Sahu Latika, $73.12 \%$ were in the age group of 2030years.In Khan et al most women belonged to age group of 31-35 years $(47 \%)$. 1,8

Sahu observed that $75.26 \%$ of belonged to para 1-3 which was comparable to our study where it is $82.5 \%$. Grand multiparity is also important risk factor for uterine rupture. Ezechi et al reported that $50.8 \%$ of patients were grandmultiparas. ${ }^{9}$ The high incidence of rupture $(59.5 \%)$ was found in primipara.

Most of the primipara belonged to post caesarean group $(57.69 \%)$, which was a leading cause of rupture uterus in our study, which was comparable to Sahu et al $(50.69 \%)$ and Salem et al (56\%). ${ }^{1}$ Women with previous lower 
segment caesarean section (LSCS) and induction of labour are more prone to rupture than spontaneous labor. ${ }^{10}$ In a study Rashmi et al, $10 \%$ of rupture were traumatic. ${ }^{11}$ Zwart et al and Katarina reported previous caesarean scar as a cause for rupture in $87.1 \%$ and $86 \%$ respectively. In countries like Yemen and Nigeria where family size is more, obstructed labor due to multiparity and malpresentations as the leading cause of rupture uterus. ${ }^{7,12}$ In Nigeria , Ghana, Ethiopia and Bangladesh, incidence of about $75 \%$ of cases of uterine rupture were associated with unscarred uterus. ${ }^{4,7,13}$

$53.83 \%$ of women with uterine rupture underwent rent repair in our study, which was comparable to other Indian studies. Most of the studies from African countries and few from Pakistan showed that significant number of rupture uterus cases managed by repair with bilateral tubal ligation. However it is not always easy to perform repair, as uterine walls are usually friable and approximation of edges may be difficult, which may result in exacerbation of post operative sepsis due to leakage of lochia into peritoneal cavity. Healing is also compromised due to sepsis. But ultimately choice for type of surgery treatment depends on type and extent of uterine rupture, degree of hemorrhage, general condition of the mother and mother's desire for future childbearing.

Study by Fabamwo et al showed that maternal mortality rate in case of rupture uterus was $30 \%$, which is quite high in comparison to our study $(3.84 \%)$. The main cause for maternal mortality is failure to diagnose the condition at first referral center and arrival at tertiary center in low condition. The perinatal mortality was observed in other studies like Sahu (94.04\%), Kodowa (93\%). It was usually due to hypoxia caused by immediate placental separation.

\section{CONCLUSION}

Rupture uterus is a rare but often catastrophic obstetric complication, has claimed innumerable loves of both mother and fetus. Keeping in view the importance of such a life threatening preventable complication the following is suggested to reduce the incidence.

Awareness about the importance of antenatal, intrapartum and postpartum care must be created among the people. Mass media education of general population about the benefits and importance of antenatal care, hospital delivery is important to reduce the problem. High risk patients especially those with previous scar, malpresentation must be managed in a tertiary health center. Reducing the primary caesarean section rate and optimizing care for women with previous caesarean section will significantly reduce the incidence of rupture uterus. Awareness about the management of labour, use of oxytocin, early referal to a well-equipped centre must be created among traditional birth attendants to reduce the incidence of uterine rupture. Contraceptive and family planning services should be made more effective to prevent unwanted pregnancies and grand multiparity.

Funding: No funding sources

Conflict of interest: None declared

Ethical approval: The study was approved by the Institutional Ethics Committee

\section{REFERENCES}

1. Sahu LA. 10 year analysis of uterine rupture at a teaching institution. $\mathbf{J}$ Obstet Gynecol India. 2006;56(6):502-6.

2. Myercough PR. Munroker's Operative Obstetrics. 2014;441-52

3. Hofmeyr GJ, Say L, Gulmezoglu M. A Systematic review: WHO systematic review of Maternal mortality and morbidity: the prevalence of uterine rupture. BJOG: An International Journal of Obstetrics and Gynaecology. 2005;112:1221-8.

4. Fofie CO, Baffoe P. A Two-year Review of uterine rupture in a Regional Hospital .Ghana Med J. 2010;44(3):98-102.

5. Rizwan N, Abbasi RM, Uddin SF. Uterine rupture, frequency of cases and fetomaternal outcome. J Pak Med Assoc. 2011;61(4):322-4.

6. Padhye SM. Rupture of the pregnant uterus:A 20 year review. Kathmandu Univ Med J. 2005;3:234-8.

7. Omole-Ohonsi, Attah. Uterine rupture: a risk factors and pregnancy outcome. Gynecol Obstetric. 2011;1:1.

8. Khan NH. Rupture of the uterus. JPMA J Pak Med Assoc. 1993;43:174-6.

9. Ezechi OC, Mabayoje P, Obsiesie LO. Rupture uterus in South Western Nigeria: a reappraisal. Singapore Med J. 2004;45:113-6.

10. Lin C, Raynor BD. Risk of uterine rupture in labour induction of patients with prior caesarean section : an inner city hospital experience .Am J Obstet Gynecol. 2004;190:1476-8.

11. Radhakrishnan RG, Aid NBV, Agrawal N. Rupture uterus changing Indian scenario. J Indian Med Assoc. 2001;99(11):634-7.

12. Diab AE. Uterine rupture in Yemen. Saudi Medical Journal. 2005;26(2):264-9.

Cite this article as: Sahu M, Natasha HK, Mandpe P. Case analysis of complete uterine rupture in a tertiary health care center. Int J Reprod Contracept Obstet Gynecol 2016;5:4401-4. 